\title{
Investigation of the Knocking Intensity Mitigation Mechanism by Dielectric Barrier Discharge
}

\author{
Eiichi Takahashi $^{1)}$ Daiki Asakawa $^{2)}$ Yukihide Nagano $^{3)}$ Toshiaki Kitagawa $^{3)}$ Taizo Nakamura $^{4)}$ \\ Makihito Nishioka ${ }^{4)}$ Fumiya Kawashima ${ }^{5)}$ Michio Nakano ${ }^{6)}$ \\ 1) National Institute of Advanced Industrial Science and Technology (AIST), Institute of Energy Conservation \\ 1-2-1 Namiki, Tsukuba, Ibaraki 305-8564 Japan (E-mail: eiichi-takahashi@aist.go.jp) \\ 2) National Institute of Advanced Industrial Science and Technology (AIST), National Metrology Institute of Japan \\ 1-1-1 Umezono, Tsukuba, Ibaraki 305-8568 Japan \\ 3) Kyushu University, Faculty of Engineering Department of Mechanical Engineering, \\ 744 Motooka Nishi-ku, Fukuoka 819-0395, Japan \\ 4) University of Tsukuba, Department of Engineering Mechanics and Energy, \\ 1-1-1 Tennodai, Tsukuba, Ibaraki, 305-8573, Japan \\ 5) Nippon Institute of Technology, Mechanical Systems Engineering Major, \\ 4-1 Gakuendai, Miyashiro-machi, Minamisaitama-gun, Saitama Pref. 345-8501 Japan. \\ 6) Nippon Institute of Technology, Department of Mechanical Engineering, \\ 4-1 Gakuendai, Miyashiro-machi, Minamisaitama-gun, Saitama Pref. 345-8501 Japan.
}

Received on June, 2 ,2020

\begin{abstract}
In our previous study, the mitigating effect of dielectric barrier discharge (DBD) on the intensity of end-gas auto-ignition was observed. In this paper, the mechanism of the effect was investigated through chemical analysis and combustion experiments using a rapid compression and expansion machine (RCEM). Comprehensive GC $\times$ GC with time of flight mass spectroscopy (GCxGC-TOFMS) was performed, and the generation of alkylhydroperoxide (ROOH) was successfully confirmed for the first time, based on accurate mass analysis. To study the mechanism of the mitigation effect, the influence of ozone was assessed using different fuel-air mixtures, such as primary reference fuel (PRF90) and surrogate gasoline (S5R). The addition of ozone showed the same mitigation effect in the case of PRF90, but a lesser effect in the case of S5R. A characteristic blue light was also observed when ozone was mixed in the end gas prior to auto-ignition. Since ozone is known to promote low temperature oxidation (LTO) reactions, the effect of DBD application likely involves the same mechanism. The difference in effect with the different fuels may be explained in terms of an ozonolysis reaction, because S5R contains olefins and PRF90 does not. Since applying DBD to the fuel-air mixture did not show a difference in effect, between S5R and PRF90, the DBD mitigation phenomena is not induced by ozone, but a plausible candidate is the ROOH. To investigate the precursor phenomena to the blue light emission, planer laser induced fluorescence measurement (PLIF) for formaldehyde (HCHO) was employed in the combustion experiment. Without DBD application, the HCHO distribution in the end gas exhibited gradual homogenization before auto-ignition; whereas, with applied DBD, the characteristic blue flame appeared in the inhomogeneous distribution of HCHO in the end-gas region. This result may support the hypothesis that the mitigating effect is caused by the promotion, by $\mathrm{DBD}$-induced $\mathrm{ROOH}$, of inhomogeneous progress in the end-gas chemical reaction.
\end{abstract}

KEY WORDS: Heat engine, Spark ignition engine, Performance, Knocking, Non-thermal plasmas (A1)

\section{Introduction}

With the recognition of global warming as an urgent issue, improvement in the thermal efficiency of internal combustion engines becomes ever more important. In this regard, knocking is an important technical issue because it limits increase in the compression ratio. Numerous studies have been conducted on this subject. Among them, using a constant volume vessel $^{(1)(2)}$, Nagano et al. found that pressure oscillation in auto-ignition was suppressed above a certain initial temperature, and confirmed the 
generation of partial fuel oxides in the vessel, using a comprehensive GCxGC system with time of flight mass spectroscopy (GCxGC-TOFMS) ${ }^{(2)}$. Based on these results, dielectric barrier discharge (DBD) was applied to fuel-air mixtures in combustion experiments using a rapid compression and expansion machine (RCEM); a technique which can generate partial oxides in the mixtures. Generating DBD in the combustion chamber before compression mitigated the pressure oscillation in the auto-ignition of the end gas. A characteristic flame-like blue-colored light was observed in the end gas, and spread throughout it before auto-ignition ${ }^{(3)(4)}$. This behavior was confirmed in various fuel-air mixtures. The mechanism of this phenomena, however, was not understood. In order to understand the mechanism of the mitigation effect, chemical analysis of the DBD-generated species in the fuel-air mixture, and elucidation of the role of such chemical species in the mitigation of the pressure oscillation intensity, are required.

We have applied ion attachment mass spectrometry (IAMS) for the chemical analysis of such DBD-generated species ${ }^{(5)(6)}$. Partial oxides, which were presumed to be fragmented species of alkyl-hydroperoxides (ROOH), were observed by IAMS. The ROOH is known as species which promote low temperature oxidation (LTO) ${ }^{(7)}$. However, the ROOH itself has thus far not been observed. In this study, the generation of $\mathrm{ROOH}$ was confirmed for the first time, using GCxGCTOFMS. In addition, to elucidate the species contribution, the effect of ozone was investigated. Ozone was introduced into the combustion chamber by adding another intake pipe with a DBD reactor, thereby producing an ozone-air mixture. Finally, the spatial distribution of formaldehyde (HCHO) in the end gas before auto-ignition was measured by planer laser induced fluorescence (PLIF), and the difference in this distribution, with and without applied DBD, was investigated.

\section{Experimental setup and procedures}

\subsection{Analysis of DBD-generated species by GCxGC-TOFMS}

Since the type and lifetime of the chemical species generated by DBD were not known, IAMS, which is less likely to cause molecular fragmentation due to ionization, was used for the analysis $^{(5)(6)}$. The results revealed the possibility that detected aldehydes and/or ketones were formed via ROOH. However, ROOH is fragmented by the attachment of alkali-ions, and the generation of $\mathrm{ROOH}$ itself has not been confirmed. Therefore, in this study, the chemical species generated by DBD were collected using the system shown in Fig. 1, and GCxGC-TOFMS analysis was performed. To this end, DBD was produced by applying sinusoidal high-voltage (12 $\mathrm{kV}_{\mathrm{pp}}, 9.5 \mathrm{kHz}$ ) with a duty ratio of $10 \%$ (discharge duration of $50 \mathrm{~ms}$ and interval of 450 $\mathrm{ms}$ ). The output gas from the DBD was diluted five times with $\mathrm{N}_{2}$ gas. The flow was kept constant during the sampling. The gas was sampled using a Tenax TA tube in a thermal desorption unit (TDU) for $30 \mathrm{~s}$.

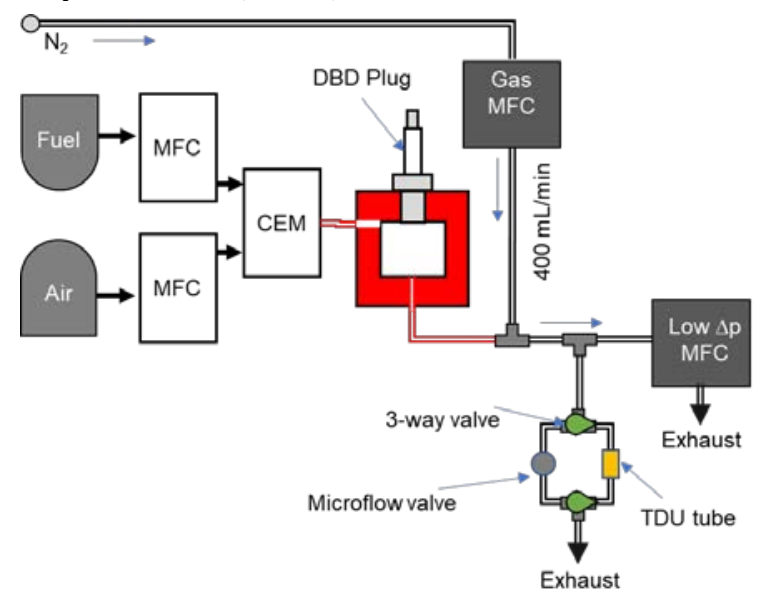

Fig.1 Schematic of gas sampling through DBD by TDU tube. MFC:Mass flow controller, CEM:Controlled evapolation and mixing

The mixture component collected in this TDU tube was injected into the GC $\times$ GC-TOFMS system (JEOL Ltd., JMS-T100GCV) by the thermal desorption method. The temperature of the TDU was increased from $30^{\circ} \mathrm{C}$ to $280^{\circ} \mathrm{C}$ at a rate of $12^{\circ} \mathrm{C} / \mathrm{s}$. He gas with a flow rate of 50 $\mathrm{mL} / \mathrm{min}$ was used as carrier gas for the desorption. A BPX5-FST-BPX-column (SGE Analytical Science) was used. The 1st column was a BPX5-30 $\mathrm{m} \times 0.25 \mathrm{~mm}$ i.d., with 0.25 $\mathrm{mm}$ thickness; and the 2nd column was a BPX50-2 m $\times 0.1 \mathrm{~mm}$ i.d., with $0.1 \mathrm{~mm}$ thickness. In this case also, the carrier gas was helium, with a flow rate of $3 \mathrm{~mL} / \mathrm{min}$. The modulation interval time was set at 8 second. The oven temperature was first maintained at $35^{\circ} \mathrm{C}$ for $2 \mathrm{~min}$, then raised to $150^{\circ} \mathrm{C}$ at $1.5^{\circ} \mathrm{C} / \mathrm{min}$, and then raised to $320^{\circ} \mathrm{C}$ at $50^{\circ} \mathrm{C} / \mathrm{min}$. The detected components were examined at an oven temperature of $48^{\circ} \mathrm{C}$ to $150{ }^{\circ} \mathrm{C}$, which was considered to provide sufficient separation for the $\mathrm{GC} \times \mathrm{GC}$. This corresponds to a retention time for the 1 st column of $8 \mathrm{~min}$ to $78 \mathrm{~min}$. The electron ionization (EI) method with an ionization energy 
of $70 \mathrm{eV}$, as is generally used, was adopted here also.

The data obtained by the detector was converted into bar type data, and then analyzed using the GC-Image (ZOEX) and Mass Center (JEOL) techniques. In the GC Image procedure, the mass spectrum of each peak was compared with the known mass spectrum in the library (library search), and the compound was identified based on the match factor (MF), expressed as a number from 0 to 999. In the Mass Center procedure, the molecular formula was estimated based on the accurate masses of the molecular ions and the main fragment ions obtained using the EI method.

\subsection{Measurement for elucidation of the DBD knocking mitigation mechanism using an RCEM}

The authors' previous study demonstrated the DBD knocking mitigation phenomena by generating DBD in an RCEM combustion chamber ${ }^{(3)(4)}$. In order to elucidate this mechanism, in this study, we investigated the phenomena when ozone, which promotes LTO reactions, was added to the fuel-air mixure. In addition, PLIF measurement was performed, in order to determine whether there was a relation between the HCHO distribution and the precursor phenomenon of blue light appearance in the end gas prior to auto-ignition.

\subsubsection{The effect of ozone mixing on knocking in} an RCEM

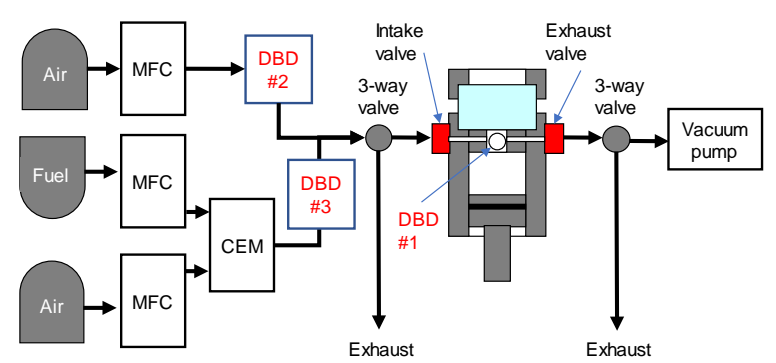

Fig. 2 Experimental piping setup for evaluating the effect of mixing ozone on knocking using an RCEM. Three DBD positions are indicated in this Fig.. The position of \#1 and \#2 are for conventional usage and ozone generation, respectively. \#3 is additional location. MFC: Mass flow controller, CEM: Controlled Evaporation

For the ozone mixing experiment, air piping was added to the intake section of the RCEM. Fig. 2 shows the gas piping around the RCEM. The positions where DBD was generated are shown as \#1 to \#3: \#1 indicates the usual combustion chamber cylinder; in \#2, ozone generated by
DBD in the air was mixed with the premixed gas; and \#3 indicates the position where DBD was generated in the premixed gas for comparison (described below). In general, $1 \mathrm{~L} / \mathrm{min}$ of air was introduced into the premix, but when supplying ozone, the amount of air introduced into the premix was halved, and the remaining half of the air was used to generate ozone.

In order to ensure gas replacement, each compression experiment was performed after twice exhausting the inside of the RCEM cylinder with a vacuum pump, and filling the chamber with fuel mixture at atmospheric pressure. In the previous study, DBD was generated at position \#1 after closing the intake and exhaust valves after filling, and compression and ignition were then performed. The temporal sequence of the present experiment is shown in Fig. 3. Ozone was introduced into the combustion chamber through the intake pipe. The sinusoidal high voltage applied to the DBD plug had an amplitude of $12 \mathrm{kV}_{\mathrm{pp}}$ and frequency of $9.5 \mathrm{kHz}$. The delay time $\Delta \mathrm{t}$ from the start of DBD to the start of compression was 6 seconds, and the discharge duration $\tau_{\text {discharge }}$ of the DBD was varied. It took roughly 1 minute to fill the the RCEM combustion chamber with the fuel-air mixture, and the DBD was stopped 0.5 seconds before the intake valve was closed, thereby ensuring that the DBD was generated in the air at roughly atmospheric pressure. A further experiment was also conducted, in which the DBD was generated at position \# 3 on the premixed gas side, for comparison. As in the previous study, ignition was generated by a spark plug installed in the upper section of the combustion chamber, and knocking was generated in the lower section of the rectangular channel. Combustion was measured using a highspeed camera with an image intensifier, through a quartz window in front of the combustion chamber. The pressure in the cylinder was also measured. As in the previous study, the interference filter installed in front of the camera lens was exchanged for measurement, and flame classification was based on Ohta's reference ${ }^{(8)}$. The cylinder temperature was $333 \mathrm{~K}$, the equivalence ratio was 0.7 , and both PRF90 (ioctane $90 \%$ and n-heptane $10 \%$ ) and surrogate gasoline S5R ${ }^{(9)}$ were used as fuel because PRF90 is composed only of paraffin, but S5R contains olefins, meaning that ozone decomposition due to the ozonolysis reaction is expected in this case. 


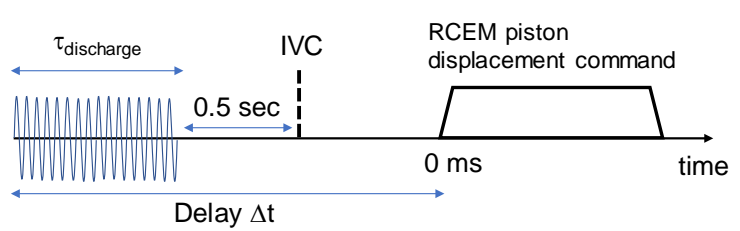

Fig. 3 Temporal sequence of ozone mixing experiment. IVC: Intake Valve Close

\subsubsection{HCHO-PLIF measurement in the end-gas region}

PLIF measurement was performed to measure the HCHO distribution in the end gas prior to auto-ignition. The basic experimental conditions were the same as in the previous report, the DBD was generated in the cylinder prior to compression, PRF90 was used as the fuel, the equivalence ratio was 0.68 , and the temperature before compression was $333 \mathrm{~K}$. Fig. 4 shows front and side cross-sectional views of the RCEM combustion chamber. The third harmonic $(\lambda=355 \mathrm{~nm}, \mathrm{E}=20 \mathrm{~mJ})$ of the $\mathrm{Nd}$ : YAG laser ( $3 \omega$ laser) was introduced from the upper quartz window. This $3 \omega$ laser pulse was generated as a double pulse using two YAG lasers, and combined on the same optical axis using a polarizer. This made it possible to measure the time evolution of the distribution during the same compression experiment. Since the $3 \omega$ laser beam was introduced from a window with a limited diameter, the lens position was adjusted using a long-focus cylindrical lens, so that the laser beam became almost sheet light in the end-gas region.

Alternatively, the usual upper spark plug installation port was replaced with a quartz window and the $3 \omega$ laser pulse was introduced, so that spark plug ignition could not be performed. In this case, the second harmonic $(\lambda=$ $532 \mathrm{~nm}$ ) of the Nd: YAG laser was introduced from the observation window on the front, and focused on the upper part of the combustion chamber channel. Then, the laser breakdown plasma ignited above the combustion chamber channel. Knocking was generated by propagating the flame from the upper to the lower part of the channel. The area enclosed by the broken red line in Fig. 4 corresponds to the spatial area visualized by the high-speed camera.
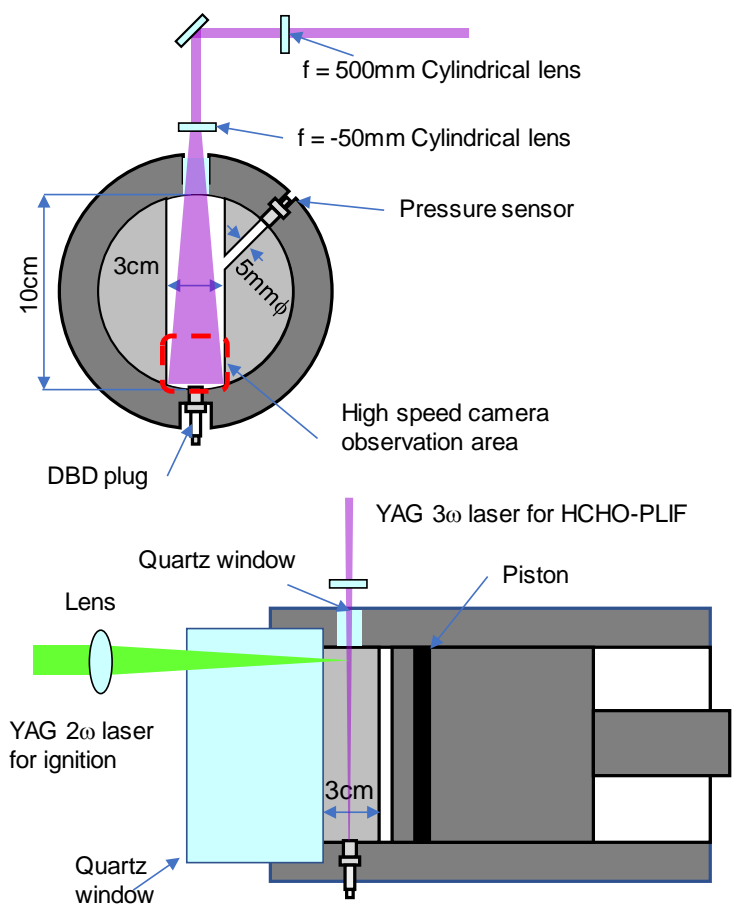

Fig. 4 Experimental setup for PLIF measurement in the combustion chamber of RCEM.

The HCHO fluorescence due to the $3 \omega$ laser was observed through an interference filter with a central wavelength of $450 \mathrm{~nm}$ with FWHM bandwidth of $40 \mathrm{~nm}$, enhanced by an image intensifier, and observed with a high-speed camera.

\section{Results}

\subsection{Analysis of DBD-generated species using GC $\times$ GC-TOFMS}

Fig. 5 shows a TIC (total ion current) chromatogram of the isooctane gas mixture that passed through the DBD. We analyzed its molecular structure for detected peaks with a ratio of more than $2 \%$ with respect to the largest peak volume. First, a library search was performed for the mass spectrum of the peak of interest. A match factor (MF) of 800 or more was considered to indicate the peak. In addition, regardless of the MF, molecular formulas were estimated using the accurate masses of molecular ions and major fragment ions obtained by the electron impact ionization (EI) method. The most plausible molecular structure for the fuel was considered to be identified when the theoretical mass difference was within $\pm 10 \mathrm{mDa}$ (dalton) of the measured value ${ }^{(10)}$. The TOFMS used in this study had a mass resolution of \pm 3 
mDa, making it possible, for example, to distinguish whether a given fragment was an oxide or not.

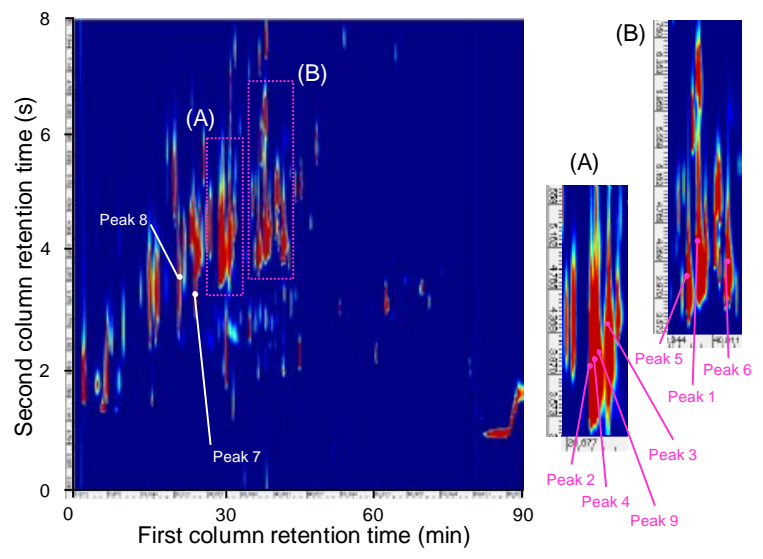

Fig. 5 TIC chromatogram of isooctane/air premixture through DBD

Table 1 List of detected chemical species

\begin{tabular}{|l|l|l|l|l|}
\hline$\#$ & $\begin{array}{l}\text { Peak } \\
\text { volum } \\
\text { e ratio }\end{array}$ & $\begin{array}{l}\text { Matc } \\
\text { Facto } \\
\text { r }\end{array}$ & $\begin{array}{l}\text { Molecula } \\
\text { r formula }\end{array}$ & $\begin{array}{l}\text { Molecular } \\
\text { Structure }\end{array}$ \\
\hline 1 & $15 \%$ & 749 & $\mathrm{C}_{8} \mathrm{H}_{18} \mathrm{O}_{2}$ & \\
\hline 2 & $11.6 \%$ & 919 & $\mathrm{C}_{8} \mathrm{H}_{18} \mathrm{O}$ & \\
\hline 3 & $11.2 \%$ & 709 & $\mathrm{C}_{8} \mathrm{H}_{16} \mathrm{O}_{2}$ & \\
\hline 4 & $9.5 \%$ & 897 & $\mathrm{C}_{8} \mathrm{H}_{18} \mathrm{O}$ & \\
\hline 5 & $5.9 \%$ & 762 & $\mathrm{C}_{8} \mathrm{H}_{18} \mathrm{O}_{2}$ & \\
\hline
\end{tabular}

Table 1 shows the estimated molecular formulas and structures for the five most intense peaks. The compounds in the table with an MF greater than 800 agreed with the molecular formulas estimated from the accurate mass of the respective ions. Those with an MF less than 800 may not be in the library. Therefore, the molecular structures of these latter compounds were determined using the molecular formulas of the respective fragment ions, as estimated based on the accurate mass, instead of the results of a library search. Using this procedure, we concluded that the \#1 and \#5 peaks were $\mathrm{ROOH}$ isomers, whose existence in the air-fuel mixture passing through the DBD was here confirmed for the first time, using $\mathrm{GC} \times \mathrm{GC}-\mathrm{TOFMS}$.

\subsection{Measurement of the DBD knocking mitigation phenomenon using the RCEM}

\subsubsection{Ozone mixing experiment}

Fig. 6 shows a comparison of the pressure history with and without ozone mixing. In this experiment, PRF90 was used as the fuel, and ignition was performed with a spark plug at time $40 \mathrm{~ms}$. Without ozone mixing (blue line), a large pressure oscillation occurs at the peak of the pressure history; whereas, with ozone mixing (red line), this oscillation is significantly reduced, and the pressure decreases at a slower rate.

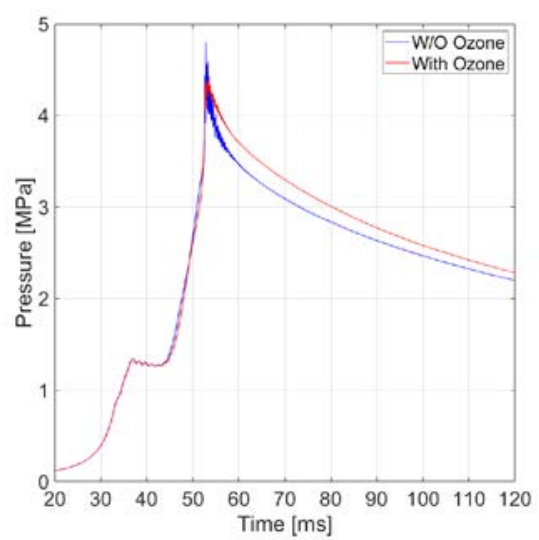

Fig. 6 Representative pressure history with and without addition of ozone.

Fig. 7 shows the results of high-speed camera observation with ozone mixing, using various interference filters. Each image shows the entire rectangular combustion channel, with the time evolution (i.e., the observed times (ms) based on the RCEM compression command start time) recorded at the bottom of the images, and the center wavelength of the respective filters shown in the upper right corner of the Fig. The characteristic emission prior to auto-ignition of the end gas is seen in the regions indicated by the red dashed line. In the previous study, a remarkable light emission was observed in the end gas region at filter center wavelengths of 394 $\mathrm{nm}$ and $330 \mathrm{~nm}$, but not at $625 \mathrm{~nm}$ (where the images especially tended to lose color). Using the classification method of Ohta et al. ${ }^{(7)}$, this emission was concluded to indicate a blue flame. In the present study, with ozone mixing, a similar characteristic light emission was observed in the 
end gas prior to auto-ignition. And in this case, the emission was also observed with the $625 \mathrm{~nm}$ interference filter. Based on the previous classification method, this blue light emission was considered to indicate a hot flame.

Comparison of the results of this ozone mixing study with those of our previous study is not simple, because both the position and duration of DBD generation are different. The discharge duration was $0.1 \mathrm{~s}$ in our previous study, meaning that it was impossible to confirm whether a blue-light emission could be observed at a filter center wavelength of $625 \mathrm{~nm}$.

Therefore, in the present study we conducted an experiment in which the DBD was generated in the premixed gas intake pipe (position \#3 in Fig. 2). As in the ozone mixing experiment, the discharge time $\tau_{\text {discharge was set }} 2 \mathrm{~s}$. In this case, high-speed camera observation at position \#3, revealed a similar blue light emission in the end gas at $625 \mathrm{~nm}$.

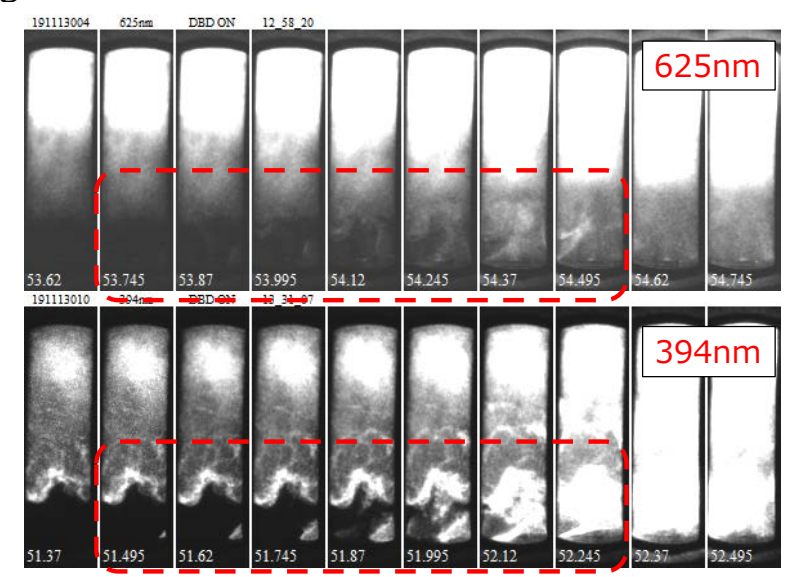

Fig. 7 Characteristic blue light emission observed in the end-gas region with ozone addition.

Therefore, it is considered that the blue light generated in the end gas in the previous study, with DBD generation in a premixed gas, also indicated a hot flame. Further, the present study revealed that ozone mixing also suppresses pressure oscillation associated with auto-ignition, as in the case of DBD application in the previous study.

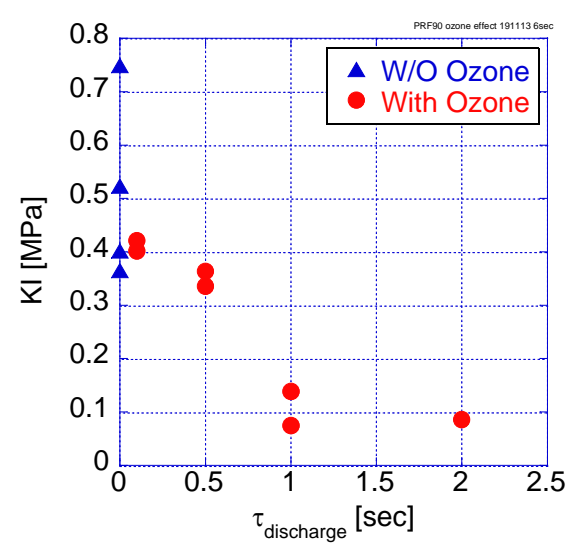

Fig. 8 The dependence of KI of PRF90 on $\tau_{\text {discharge }}$ of DBD for ozone generation.

Fig. 8 and Fig. 9 show the dependence of the knocking index (KI) on the discharge time $\tau_{\text {discharge }}$ of DBD in the air, which generated ozone. The $\mathrm{KI}$ is defined as a maximum pressure oscillation amplitude of greater than $5 \mathrm{kHz}$. In Fig. 8, PRF90, and in Fig. 9, S5R, was used as fuel. The blue-triangle and red-dot data points indicate the KI without and with ozone mixing, respectively. As can be seen in Fig. 8 (PRF 90), with ozone mixing, the KI decreases significantly with the increase in discharge time, compared to the case without ozone mixing.

In contrast, in Fig. 9 (S5R), the suppression effect is weak, suggesting that ozone decomposition occurred before compression, due to the ozonolysis reaction involving olefins in the S5R. The ozonolysis reaction rate, which is weakly dependent on the position of the double bond in the olefin molecule, is roughly in the order of $10^{-16} \mathrm{~cm}^{3} /$ molecules sec $^{(11)}$. Even assuming that the fuel's olefin content is 12 $\mathrm{mol} \%$, it is estimated that the ozone decomposes in about a second.

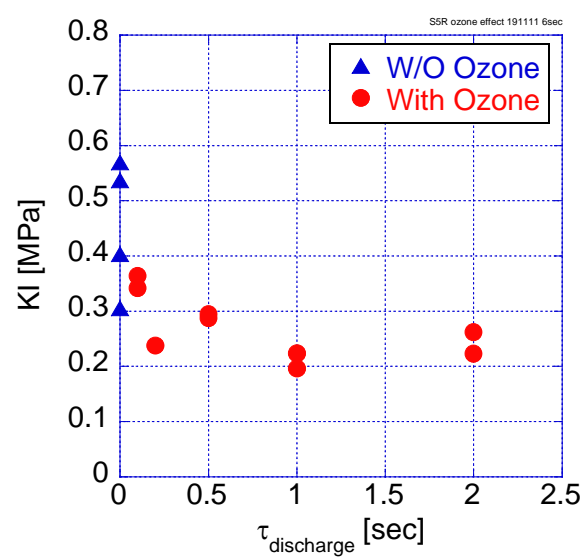

Fig. 9 The dependence of KI of S5R on $\tau_{\text {discharge }}$ of DBD for ozone generation. 


\subsubsection{Temporal development and spatial} distribution of $\mathrm{HCHO}$ in the end-gas region

Fig. 10 shows PLIF emission images of the end gas, without DBD application. The images were obtained by introducing a $3 \omega$ laser into the end gas immediately before auto-ignition, at different times in multiple experiments conducted under the same conditions. The flame is propagating from the top, and the tip of the DBD plug can be seen at the bottom. A line is visible on the wall, due to the sheet laser's illumination of the lower part of the combustion chamber. In the image at time $51 \mathrm{~ms}$, almost no luminescence is seen in the end gas, but the intensity of the luminescence increases from 52 ms onward. The emission is non-uniform (dark and bright patches) at $52 \mathrm{~ms}$, but then becomes increasingly uniform as time progresses. Although not shown, the end gas self-ignites immediately after this image sequence.

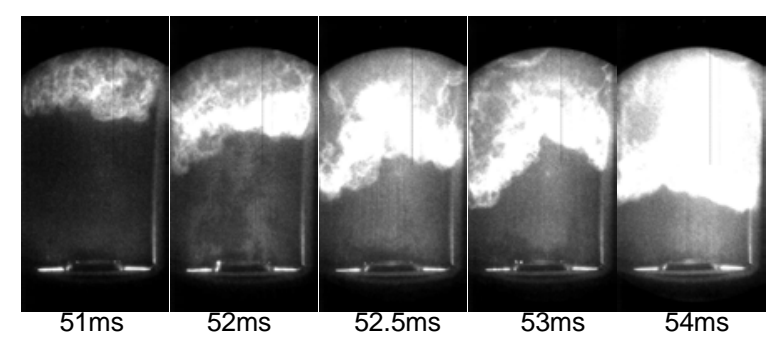

Fig. 10 Temporal development of HCHO in the end gas, without DBD application.

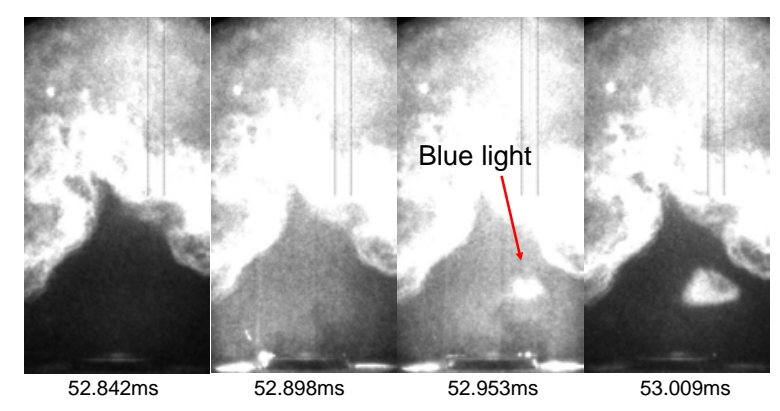

Fig. 11 The spatial distribution of HCHO and the blue light generation in the end-gas, with DBD generation.

Fig. 11 shows the double-pulse PLIF observation results for the case with DBD application. Several trials were repeated, and a case was selected in which the $3 \omega$ laser beam was luckily incident when the blue light appeared in the end gas. The image was acquired at 18000 fps, and the time interval between frames is approximately $56 \mu \mathrm{s}$. It can be seen that the generation of blue light begins before the $\mathrm{HCHO}$ emission distribution in the end gas becomes uniform. We obtained numerous results showing a similar time evolution, but could not find a change in the intensity of HCHO emission preceding the appearance of the blue light. This may be due to the fact that the combustion channel extended beyond the region of the laser sheet, meaning that the two did not fully overlap.

\section{Discussion}

In order to elucidate the role of DBD generation in the pre-mixture (vs. air) in suppressing pressure oscillation due to selfignition, chemical species analysis was performed in parallel with combustion experiments involving various fuel-air mixtures in an RCEM. We hypothesized that the $\mathrm{O}$ radicals generated by the DBD underwent the $\mathrm{H}$ abstraction reaction with the fuel molecules to form ROOH and/or other species, which promoted an LTO reaction in the end gas, resulting in spatial non-uniformity and, in turn, non-uniform ignition. This hypothesis, along with the mitigation of pressure oscillation due to the non-uniform process, was not confirmed in either the previous or present study. However, the formation of ROOH by the DBD generated in the fuel-air mixture was confirmed by GC $\times$ GCTOFMS. Next, a comparative experiment was conducted using ozone generated by DBD in air. Ozone showed similar suppression of the pressure oscillation of auto-ignition, and blue light emission in the end gas was similarly observed. Ozone is assumed to be dissociated by the temperature rise due to compression, generating $\mathrm{O}$ radicals and promoting the LTO reaction. Therefore, it is likely that the application of DBD in the premixed gas would involve a similar mechanism to ozone mixing in terms of the mitigation effect. Further, in the previous study, with DBD application in the airfuel mixture, there was no difference in the mitigation effect using PRF90 or S5R (containing olefins); whereas, a difference was observable in this ozone mixing experiment. It is thus considered that the mitigation effect of DBD in the air-fuel mixture was not induced by ozone. Finally, using HCHO-PLIF measurement, we observed that the HCHO emission distribution in the end gas became uniform over time. Moreover, with applied DBD, the characteristic blue light appeared during non-uniform HCHO distribution, supporting the hypothesis that the pressure oscillation is suppressed by causing non-uniform ignition. 


\section{Conclusion}

In order to elucidate the mitigating effect of DBD application on the intensity of end-gas auto-ignition, the mechanism of the effect was investigated using chemical analysis in combustion experiments in an RCEM. The following findings were obtained.

1. When GC $\times$ GC-TOFMS was performed on the DBD-generated species in the fuel-air mixture, the formation of $\mathrm{ROOH}$ was confirmed for the first time, based on accurate mass analysis.

2. Ozone mixing exhibited a mitigation effect similar to DBD application, suggesting enhancement of the LTO reaction. However, the fuel-independence of the DBD effect suggested that, in that case, the mitigation effect was not induced by ozone.

3. Without applied DBD, the HCHO distribution in the end gas exhibited gradual homogenization before auto-ignition. In contrast to the case with DBD application, here the characteristic blue light was observed during the inhomogeneous distribution of HCHO in the endgas region. This result may support the hypothesis that the mitigation effect is the result of DBD-induced ROOH promoting inhomogeneous progress in the chemical reaction in the end gas.

This paper is based on proceedings of the JSAE 2020 Annual Congress.

\section{References}

(1) Y. Nagano, R. Shinya, K. Kono, S. Tanaka, T. Kitagawa: Study on Crucial Factor of Knock Intensity Using Constant Volume Vessel, Transactions of Society of Automotive Engineers of Japan, Vol. 49, No. 4, p. 714719, (2018) (in Japanese)

(2) Y. Nagano, T. Kitagawa, M. Nakano: Propagating Flame and End-gas Autoignition in Constant Volume Vessel, Journal of the Combustion Society of Japan, Vol. 57, No. 181, p. 199-205 (2015) (in Japanese)

(3) E. Takahashi, Y. Nagano, T. Kitagawa, M. Nishioka, T. Nakamura, M. Nakano: The 30th Internal Combustion Engine Symposium 97, (2019) (in Japanese)

(4) E. Takahashi, Y. Nagano, T. Kitagawa, M. Nishioka, T. Nakamura, M. Nakano, Combust. Flame, 216, p.185-193 (2020).
(5) D. Asakawa, A. Kuramochi, E. Takahashi, N. Saito: Phys. Chem. Chem. Phys. 20 p.10821090 (2018).

(6) D. Asakawa, N. Saito, E. Takahashi: J. Phys. Chem. A 124, p. 2019-2028 (2020).

(7) S. M. Aceves , D. Flowers , J. Martinez-Frias, F.Espinosa-Loza: W. J. Pitz, R. Dibble, Fuel and Additive Characterization for HCCI Combustion. SAE Technical Paper, 2003-011814 (2003)

(8) Y. Ohta, M. Furutani: Identification of cool and blue flames in compression ignition, Arch. Combust. 11 p. 43-52 (1991)

(9) A. Miyoshi http://www.akrmys.com/kinm/modl.html.en

(10) F. Kawashima, K.Monzen, M. Nakano: Study of Nitrated Hydrocarbons Produced by Engine Combustion, the Fifty-Seventh Symposium (Japanese) on Combustion, No.D115 (2019) (in Japanese)

(11) E.V. Avzianova, P.A. Ariya: Temperaturedependent kinetic study for ozonolysis of selected tropospheric alkenes. International Journal of Chemical Kinetics 34(12), p. 678684 (2002) 